\title{
Some interesting lepiotoid mushrooms from North India
}

\section{Kumari B, Atri NS and Kaur M}

Department of Botany, Punjabi University, Patiala, Punjab-147002 (India) babita.thkr@gmail.com, narinderatri04@yahoo.com, munruchi@gmail.com, Tel. no. +918894176765, Fax no. 0175-3046265

Kumari B, Atri NS, Kaur M 2012 - Some interesting lepiotoid mushrooms from North India. Mycosphere 3(6), 949-955, Doi 10.5943 /mycosphere/3/6/9

Three lepiotoid mushrooms namely, Lepiota roseifolia, L. plumbicolor and L. atrodisca collected from different localities of North India are described and illustrated. All are new records for India.

Key words - Agaricaeae - fleshy fungi - India - Lepiotoid mushrooms - Taxonomy

Article Information

Received 24 October 2012

Accepted 29 October 2012

Published online 28 November 2012

*Corresponding author: Kumari B - e-mail - babita.thkr@gmail.com

\section{Introduction}

The genus Lepiota (family Agaricaceae), is represented by 400 species worldwide (Kirk et al. 2008). The diagnostic characteristics of Lepiota are fleshy lamellate vividly coloured carpophores, squamulose pileus, annulate stipe, light coloured ellipsoid to amygdaliform double walled spores with or without germ pore, mostly metachromatic endosporium, absence of pleurocystidia and presence of cheilocystidia in most of the cases. During a survey of agarics flora of North India (2008-2011), three interesting lepiotoid mushrooms namely, Lepiota roseifolia Murrill, L. plumbicolor (Berk. \& Br.) Sacc. and $L$. atrodisca Zeller were discovered. Being new records for India they are illustrated and described.

\section{Materials and methods}

For the collection, preservation and description of agarics standard methods were employed (Atri et al. 2005). Macroscopic examination was carried out on fresh specimens. Microscopic characters were studied from free-hand sections mounted in $10 \% \mathrm{KOH}$, stained with $1 \%$ Congo red. Colour terminology used in the taxonomic description is based on Methuen Handbook of colours (Kornerup \& Wanscher 1978). The specimens have been deposited in the Herbarium of Botany Department, Punjabi University Patiala under PUN.

\section{Taxonomic observations}

Lepiota roseifolia Murrill, Mycologia 4: 235, 1912.

Figs. 1a, 2a-e

Fructifications $6-9 \mathrm{~cm}$ in height. Pileus 2.5-4.0 cm broad, convex with brown (6E4) umbo, surface covered by concentrically arranged brownish appressed fibrillose scales over whitish background; margin irregular, splitting at maturity; cuticle fully peeling; flesh up to $2 \mathrm{~mm}$ thick, white (4A2), immediately changing to pinkish red to orangish on bruising; taste and odour mild. 

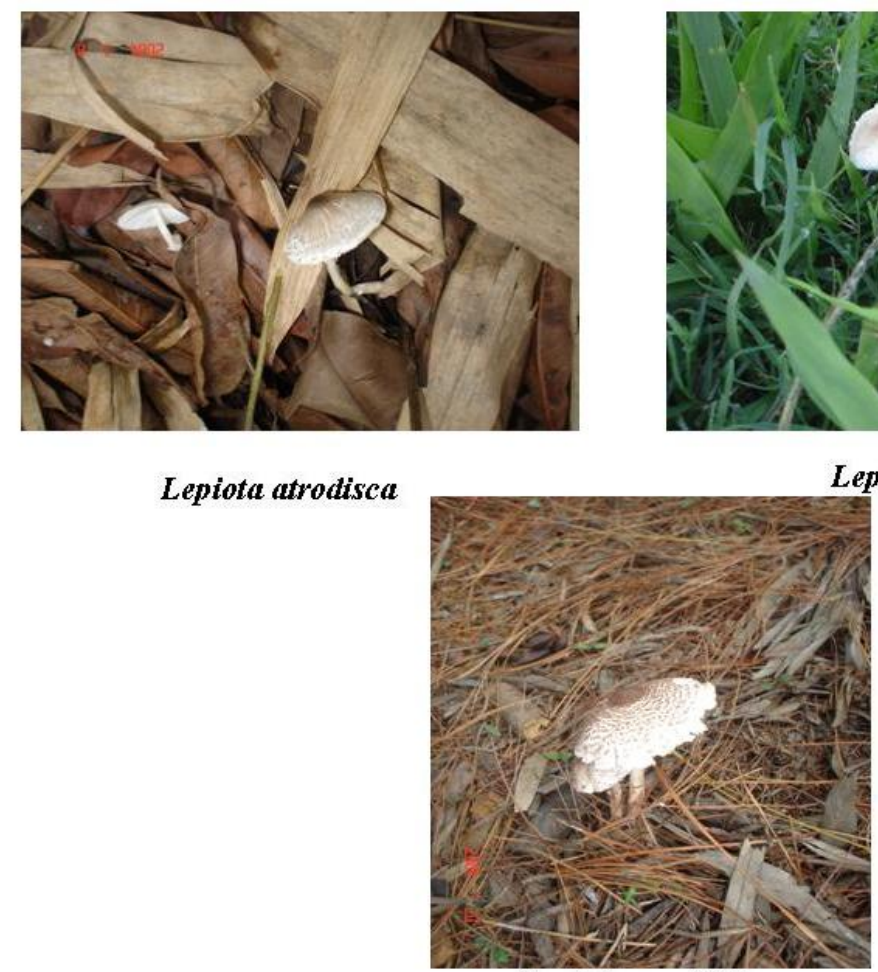

Lepiota roseifolia

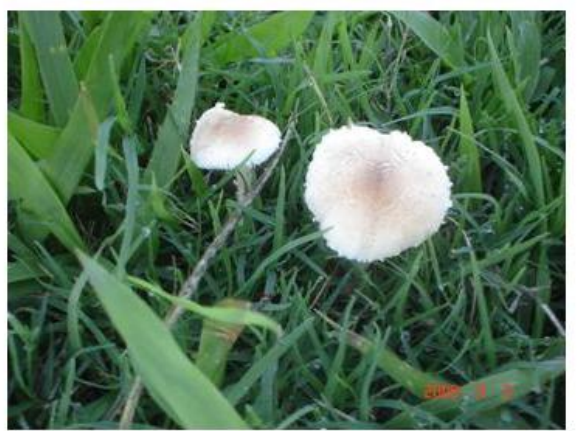

Lepiota plumbicolor

Fig. 1a-c-Field photographs of (a) Lepiota atrodisca, (b) L. pumbicolor and (c) L. roseifolia

Lamellae free, subdistant to crowded, unequal, with lamellulae of 2-3 lengths, up to $5 \mathrm{~mm}$ broad, yellowish white (4A2), reddish on bruising; gill edges serrate; spore deposit cream. Stipe central, $5.3-8.3 \mathrm{~cm}$ long, 3-4 mm broad, orange white (5A2), scaly, scales brownish, more towards the base, reddish on bruising; hollow, obclavate; annulate, annulus single, attached (Figure 1a; 2a).

Basidiospores 5.6-8.0 × 3.2-4.8 $\mu \mathrm{m}(\mathrm{Q}$ $=1.7$ ), thin-walled, smooth pseudoamyloid to dextrinoid, ellipsoid to amygdaliform, not metachromatic in cresyl blue, apical pore inconspicous. Basidia 15.2-24.2 × $6.4-8.0$ $\mu \mathrm{m}$, inamyloid, thin-walled, clavate, tetrasporic; sterigmata 3.2-4.8 $\mu \mathrm{m}$ long; gill edges sterile. Cheilocystidia 19.3-27.3 $\times 8.0$ $14.5 \mu \mathrm{m}$, inamyloid, clavate to pyriform. Pleurocystidia absent (Fig. 2b,d).

Pileus cuticle composed of trichoderm consisting of septate elongated hyphae with rounded or tubular tips (Fig. 2e); context homoiomerous; subhymenium pseudoparenchymatous, well developed, composed of loosely arranged elements. Stipe cuticle hyphae parallel running, 4.0-20.0 $\mu \mathrm{m}$ broad. Clamp connections absent.
Collection examined - Himachal Pradesh, Palampur, IHBT road (1200 m), growing scattered under Pinus roxburhgii, Babita Kumari, PUN 4634, 27 July 2009.

Remarks - The above examined collection is typical of $L$. roseifolia which closely resembles the details given by Murrill (1912). It can be easily recognized in the field by its carpophore parts changing to pinkish red to orangish on bruising. Overall the pileus is covered by brownish appressed fibrillose scales over yellowish white background, trichodermal palisade consisting of septate upright hyphae with rounded to tubular tips. It is often confused with L. flammeatincta in outward morphology from which it mainly differs in bruising in all parts of the carpophore instead of stipe and cap surface only. It is a new fungus record for India.

Lepiota plumbicolor (Berk. \& Br.) Sacc., Syll. Fung. 5: 63, 1887

Fructifications $2.2-3.2 \mathrm{~cm}$ in height. Pileus $1.2-2.0 \mathrm{~cm}$ in diameter, convex, surface orange white (5A2) with greyish to purplish umbo over the yellowish white background, scaly; scales light brown, appressed fibrillose 


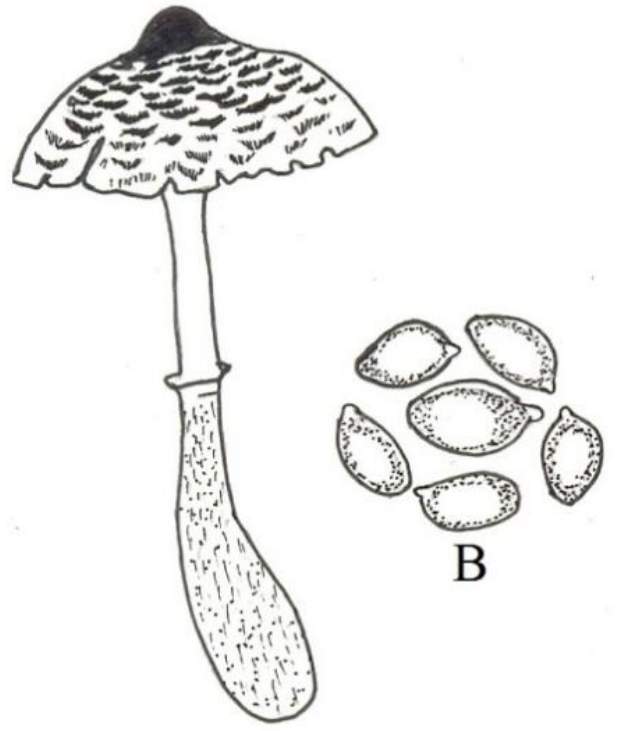

A
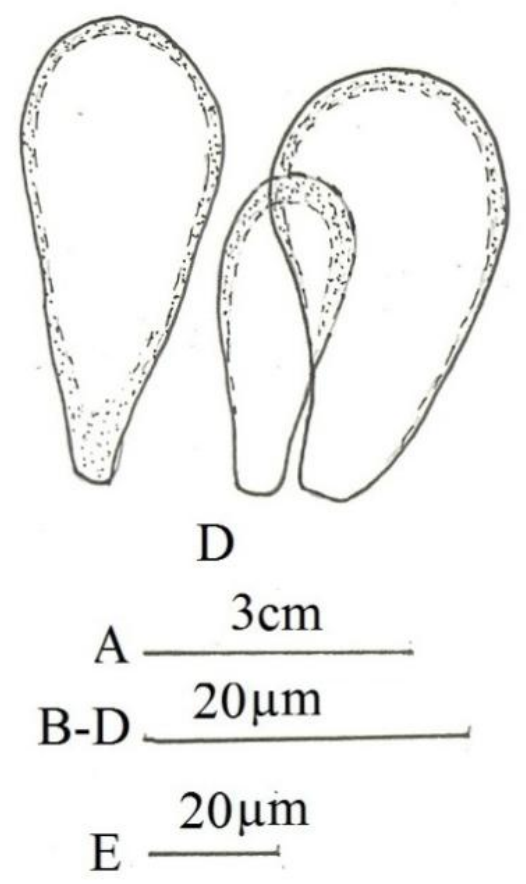

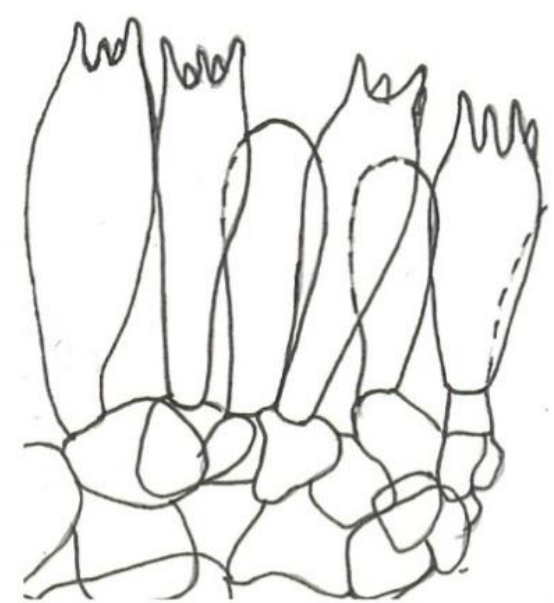

C

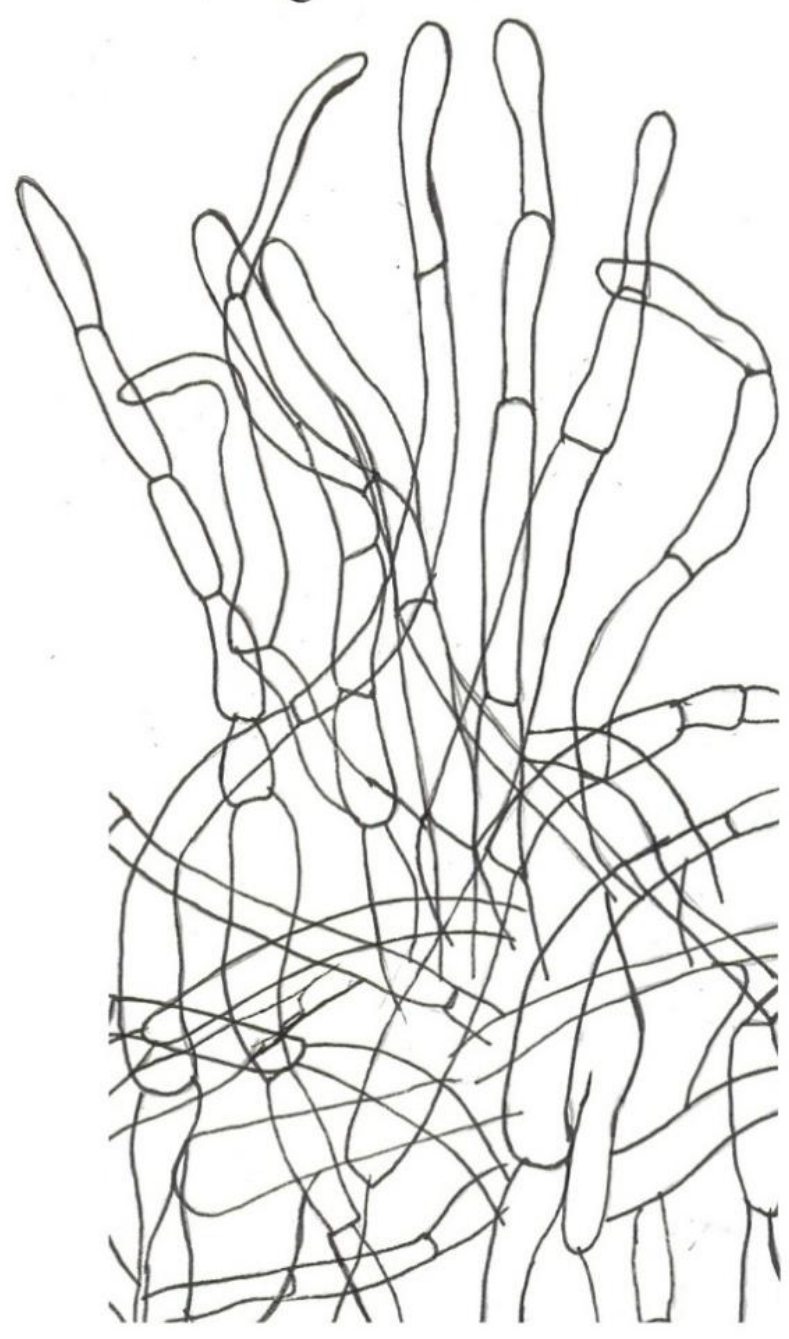

E

Figs 2A-E - Lepiota roseifolia. A Carpophore. B Basidiospores. C Basidia. D Cheilocystidia. E Pileus cuticle elements. 
to warty squamulose; margin irregular, splitting at maturity; cuticle fully peeling; flesh yellowish white, unchanging, up to $2 \mathrm{~mm}$ thick; taste and odour mild. Lamellae free, collariate, unequal, with lamellulae of $0.2-0.3$ $\mathrm{cm}$ in length, subdistant, 4-6 $\mathrm{mm}$ broad, yellowish white (4A2), unchanging; gill edges serrate; spore deposit white (1A1). Stipe central, $2-3 \mathrm{~cm}$ long, $0.2-0.3 \mathrm{~cm}$ broad, yellowish white (4A2) to orange-white (6A2), brownish on bruising, fleshy, equal in diameter throughout with a slightly bulbous base, hollow, pruinose fibrillose, fibrills soon disappear upon handling; annulus fibrillose, soon evanescent(Fig. 1b, 2a).

Basidiospores 8.0-9.6 × 4.8-6.4 $\mu \mathrm{m}(\mathrm{Q}$ $=1.6$ ), broadly ellipsoid, double walled, outer wall thick without apical pore, dextrinoid, congophilous, non metachromatic in cresyl blue. Basidia 12.5-37.0 × 7.2-8.8 (-9.6) $\mu \mathrm{m}$, broadly clavate, granular, tetrasporic; sterigmata up to $3 \mu \mathrm{m}$ long; gill edges sterile. Cheilocystidia crowded, 25.8-40.3 × 8.0-11.3 $\mu \mathrm{m}$, thin-walled, broadly clavate, pyriform, utriform with pedicellate cells and clamp connections, inamyloid. Pleurocystidia absent (Fig. 3b-e).

Pileus surface a hymeniform trichoderm formed of broadly clavate globose to elongated cylindrical septate elements measuring 24.2-92.6 $\times 8.8-16.0 \mu \mathrm{m}$ in size, often with clamp connections (Fig. 3e); context homoiomerous; gill trama parallel, inamyloid. Stipe hyphae thick-walled, septate, consisting of caulocystidia $40.0-62.0 \times 8.0-16.0 \mu \mathrm{m}$ in size, clavate to pyriform septate elements, scattered. Clamp connections present.

Collection examined - Patiala, GTB Hall, Punjabi University campus (250 m), growing scattered on soil, Babita Kumari, PUN 4635, 9 September 2009.

Remarks - The above collection belongs to Section Ovisporae of genus Lepiota (Pegler 1986). It has a miniature stature with orange-white to greyish orange pileus with purplish tinge on the disc having trichodermial hymeniform pileipellis formed of long clavate elements and presence of caulocystidia. It is a new fungus record for India.
Lepiota atrodisca Zeller Mycologia 30: 473, 1938.

Fig. 1c, 4a-e

Carpophores $7.8-8.9 \mathrm{~cm}$ in height. Pileus 2.5-3.1 cm in diameter, convex, umbonate, brownish grey (7D2) to dark blakish on the disc, surface covered by patches of light brownish grey scales over yellowish white (4A2) background, moist; margin regular, splitting at maturity, inrolled; cuticle fully peeling; flesh up to $0.1 \mathrm{~cm}$ thick, off white, unchanging; taste and odour mild. Lamellae free, crowded, unequal, of 3-4 lengths, yellowish white (4A2), unchanging up to 0.2 $\mathrm{cm}$ broad; gill edges smooth, fragile. Stipe central, $7.8-8.6 \mathrm{~cm}$ long, $0.2-0.3 \mathrm{~cm}$ broad, yellowish white (4A2), concolourous with the pileus, turns yellowish brown on handling, obclavate, hollow, scaly; annulate, annulus single, membranous, often with a greyish black margin, attached, superior (Fig. 1c, 4a).

Basidiospores 5.6-8.0 × 3.2-4.8 $\mu \mathrm{m}(\mathrm{Q}$ $=1.6$ ), ellipsoid with single guttule, dextrinoid, strongly congophilous, not metachromatic in cresyl blue, apical pore absent. Basidia 12.8$24.9 \times 6.4-8.0 \mu \mathrm{m}$, clavate, tetrasporic; sterigmata $3.2-4.8 \mu \mathrm{m}$ long; gill edges sterile. Cheilocystidia $22.5-37.0 \times 4.8-11.3 \mu \mathrm{m}$, clavate, lageniform, subcapitate, crowded, often in clusters. Pleurocystidia absent (Fig. $4 b-d)$.

Pileus cuticle composed of a disrupted trichoderm made up of branched, apical clavate to cylindrical elements with obtuse ends measuring 4.8-11.3 $\mu \mathrm{m}$ in size (Fig. 4e); context homoiomerous; gill trama regular; subhymenium pseudoparenchymatous. Stipe surface hyphae running parallel throughout measuring 4.8-11.2 $\mu \mathrm{m}$ in width, clamp connections absent throughout.

Collection examined - Himachal Pradesh, Mandi, Sarkaghat, Bakarta $(850 \mathrm{~m})$, growing scattered on leaf litter of Syzigium cumini, Babita Kumari, PUN 4418, 14 July 2009.

Remarks - The above collection is typical of $L$. atrodisca as described by Zeller (1938). It is characterized by medium sized carpophores having a cap with fine, greyish black scales, annulate stipe often with a greyish 

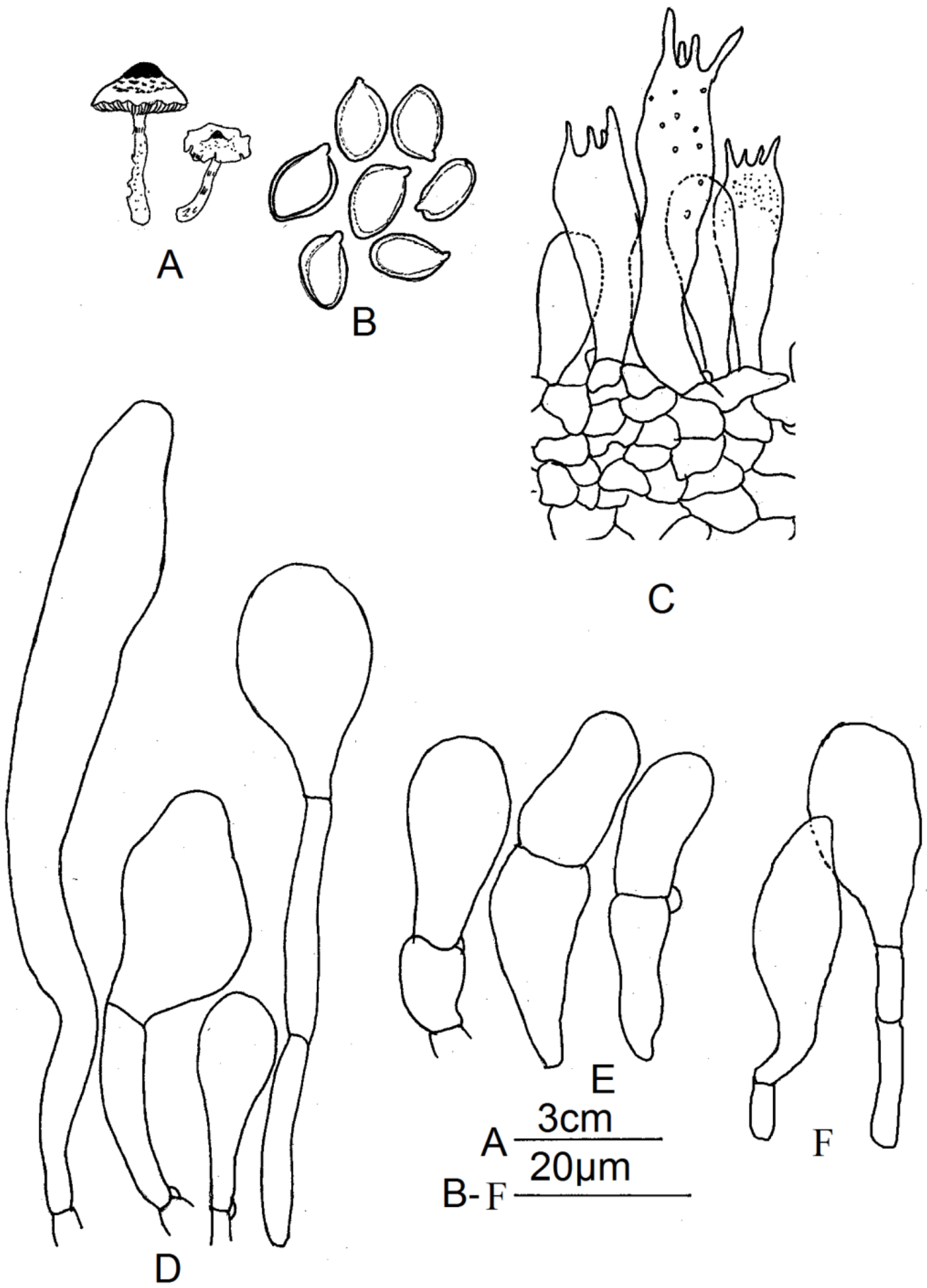

Figs 3A-F - Lepiota plumbicolor. A Carpophores. B Basidiospores. C Basidia. D Cheilocystidia. E Pileus cuticle elements. F Caulocystidia. 


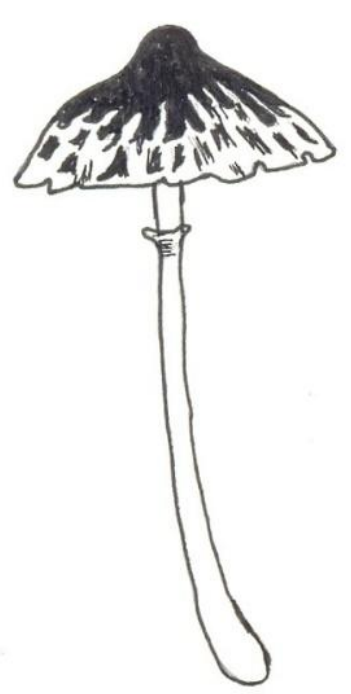

A
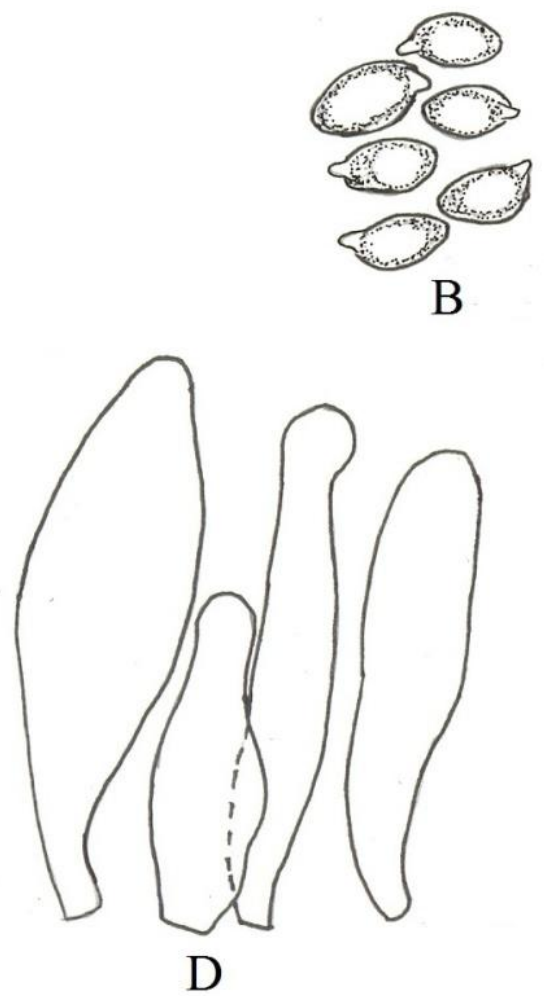

$$
\text { A } \frac{3 \mathrm{~cm}}{20 \mu \mathrm{m}}
$$

B- E

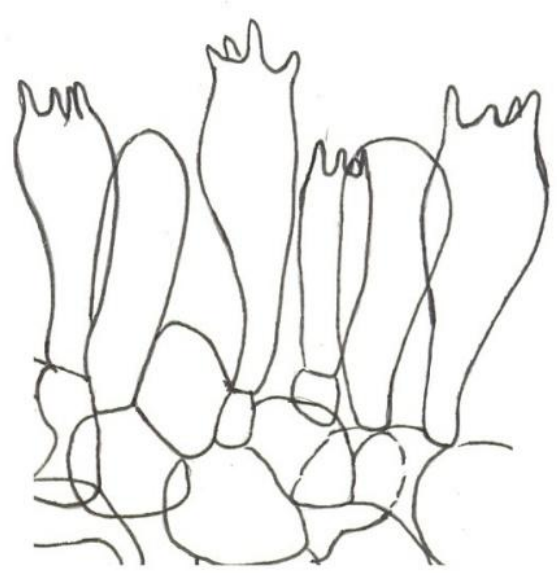

C

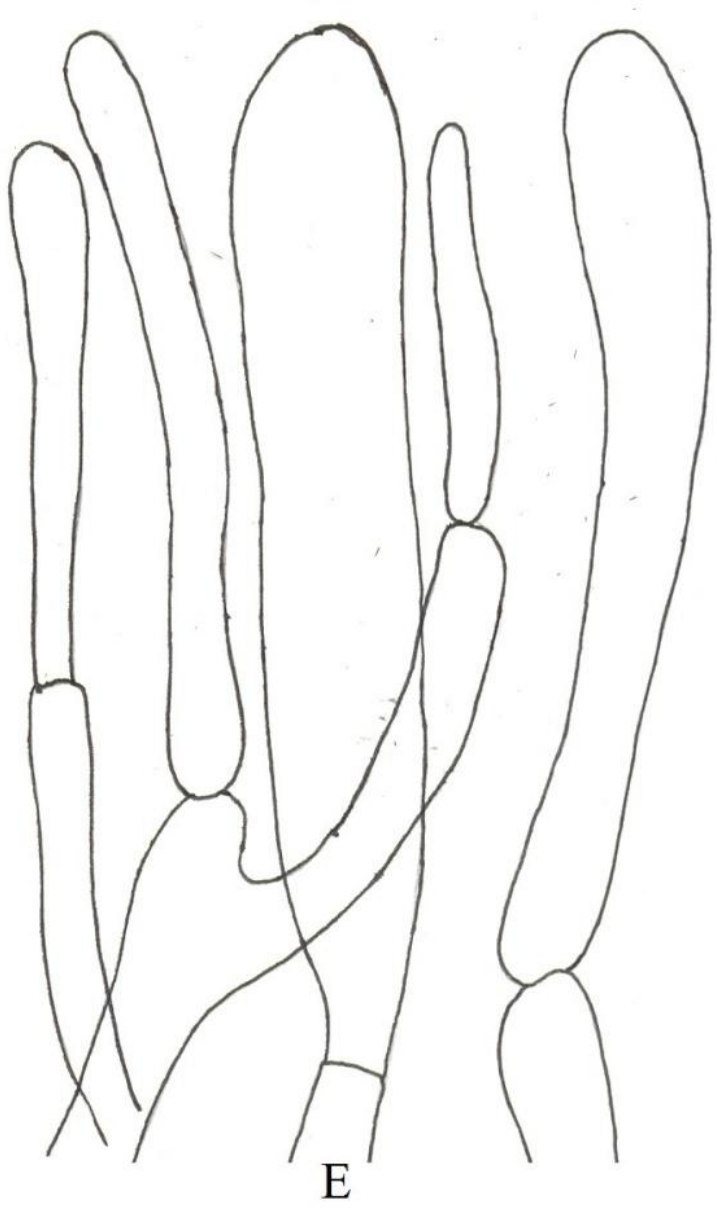

Figs 4A-E - Lepiota atrodisca. A Carpophore. B Basidiospores. C Basidia. D Cheilocystidia. E Pileus cuticle elements. 
Mycosphere Doi 10.5943/mycosphere/3/6/9

brown annular margin. It is a new fungus record for India.

\section{Acnowledgements}

Authors wish to thank Head, Department of Botany, Punjabi University, Patiala for providing laboratory facilities and University Grants Commission for financial assistance under SAP-III programme of D.R.S. in which Mycology and Plant Pathology is one of the thrust area.

\section{References}

Kirk PM, Cannon PF, Minter DW, Stalpers JA. $2008-$ Dictionary of the Fungi.10 ${ }^{\text {th }}$ edn. CAB International, Wallingford, UK.
Atri NS, Kaur A, Kaur H. 2005 - Wild Mushrooms Collection and Identification. Frontiers in Mushroom Biotechnology. (RD Rai, RC Upadhyay,SR Sharma, eds ). NRCM Chambaghat, Solan, pp. 9-26.

Kornerup A, Wanscher JH. 1978 - Methuen Handbook of Colour $3^{\text {rd }}$ edn. Eyre Methuen, London.

Murrill WA 1912 - The Agaricaceae of Pacific coast - II. Mycologia 4, 231262.

Pegler DN. 1986 - Agaric flora of Sri Lanka. Kew Bulletin Additional Series 12. HMSO London. pp. 519.

Zeller SM. 1938 - New or noteworthy Agarics from the Pacific Coast States. Mycologia 30, 468-474. 